\title{
Entre o canto e a caneta: oralidade, escrita e conhecimento entre os Guarani Mbya*
}

Adriana Queiroz Testa

Universidade de São Paulo

\section{Resumo}

0 tema das relações entre oralidade e escrita é apresentado em grande parte dos estudos e programas dedicados à questão da educação escolar indígena, mas raramente é tomado como problema central para a compreensão dos processos de ensino-aprendizagem nos contextos em que a escola se faz presente. Por outro lado, autores que se dedicam a essa questão enfatizam quase exclusivamente a escrita em detrimento da oralidade. Nesse sentido, associada à necessidade de uma discussão teórica de maior fôlego, percebe-se a falta de análises que se dediquem à compreensão do papel e dos significados da escrita e da oralidade entre diferentes povos indígenas. No intuito de contribuir para o aprofundamento e a ampliação desse debate, o presente artigo procura discutir a temática, pautando-se numa abordagem que permite caminhar entre a leitura de textos especializados e relatos que registram interpretações de pessoas Guarani Mbya. Os relatos colhidos e textualizados durante sete anos de pesquisa e convivência com os Mbya em diferentes aldeias das regiões sul e sudeste permitem repensar a oralidade e a escrita como aspectos importantes num conjunto mais amplo de processos de produção, aquisição e transmissão de conhecimento. Desse ponto de vista, a educação é concebida num sentido amplo que não se reduz à escolarização.

\section{Palavras-chave}

Educação escolar indígena - Oralidade - Escrita - Guarani Mbya.

\footnotetext{
Correspondência:
}

Adriana Queiroz Testa

Rua Barroso Neto, 342, ap. 124

05585-010 - São Paulo - SP

e-mail: a.testa@ig.com.br

* Esta pesquisa foi desenvolvida com 0

apoio financeiro da FAPESP. 


\title{
Between Iyrical and literate: orality, writing and knowledge among the Mbya Guarani*
}

Adriana Queiroz Testa

Universidade de São Paulo

\begin{abstract}
The theme of the relations between orality and writing can be found in most studies and programs dedicated to the issue of the school education of indigenous populations, but it has seldom been taken as the central problem in understanding the teaching-learning processes in the contexts where schools take part. In fact, authors that deal with this question emphasize almost exclusively writing, and tend to forget about orality. In this sense, associated to the need for a deeper theoretical discussion, one can observe the lack of analyses dedicated to comprehend the role and meaning of writing and orality among the various indigenous peoples. With the purpose of contributing to expand and advance the debate, this article seeks to discuss the theme based on an approach that allows us to move between the reading of specialized texts and reports that register interpretations by Mbya Guarani individuals. The testimonies collected and transcribed during seven years of research and living with the Mbya in different villages in the South and Southeast regions of the country allowed us to reconceptualize orality and writing as important aspects within a wider group of processes of production, acquisition and transmission of knowledge. From this viewpoint, education is conceived in a wide sense that cannot be reduced to schooling.
\end{abstract}

\section{Keywords}

Schooling of indigenous peoples - Orality - Writing - Mbya Guarani.

Contact:

Adriana Queiroz Testa

Rua Barroso Neto, 342, ap. 124

05585-010 - São Paulo - SP

e-mail: a.testa@ig.com.br

"This research was sponsored by FAPESP. 
Xeramoi [nosso pajé] sempre fala para nós que as palavras dos livros duram pouco. Ele fala que pode deixar os juruá [pessoas não indigenas] escreverem seus livros, porque um dia tudo isso vai acabar. 0 papel rasga, queima ou se molha na água e derrete, já a palavra que é falada dentro de cada um não morre. Ela passa por dentro de mim e passa por dentro dos outros e, mesmo quando eu morrer, as palavras que forem verdadeiras vão continuar circulando entre meus filhos e netos. (Verá Mirim, Aldeia Tekoá Pyaú, 2006)

No contexto atual de políticas públicas de educação escolar indígena, no qual a proposta de uma educação diferenciada, específica, bilíngüe e intercultural freqüentemente enfatiza a alfabetização em língua indígena e o registro escrito de conhecimentos indígenas como meios de "valorização e preservação" culturais, a citação de Verá Mirim nos indica a necessidade de colocar certos pressupostos em suspensão, de forma que possamos vê-los e revê-los partindo de outros lugares ou perspectivas.

As considerações apresentadas neste artigo são uma reelaboração de questões abordadas na pesquisa de mestrado Palavra, sentido e memória: educação e escola nas lembranças dos Guarani Mbya (Testa, 2007). Por meio de um trabalho de coleta e textualização de narrativas e experiências com colaboradores que vivem em diferentes aldeias das regiões sul e sudeste, foi possivel acompanhar como temas fundamentais aos processos de conhecimento - tais como memória, esquecimento, oralidade, escrita, experiência, tradução, saber e poder se fazem presentes na vida de professores e outras pessoas guarani mbya que não estão necessariamente ligadas à educação escolar.

Tomando essas narrativas e experiências como ponto de partida, é possivel tecer observações sobre as (im)possíveis relações entre educação escolar e outros processos de produção, aquisição e transmissão de conhecimento desenvolvidos pelos Guarani Mbya. Assim, ao problematizar temas caros aos debates sobre educação escolar indígena, percebe-se a necessidade de pensá-los no âmbito de um contexto educacional mais amplo que não se restringe à escolarização.

Desse modo, o presente artigo busca discutir o tema das relações entre oralidade e escrita, caminhando entre textos especializados e considerações apresentadas por pessoas Guarani Mbya no seu pensar os processos de produção, aquisição e transmissão de conhecimentos'. No intuito de contextualizar o tema central deste artigo, inicio com uma discussão geral sobre o conhecimento como processo, tomando como norte a noção mbya de que o conhecimento pode ser entendido não como um objeto a ser acumulado e transmitido, mas como possibilidade relacional de busca e comunicação.

\section{Conhecimento como busca e comunicação}

Tomar o conhecimento como tema de estudo não se restringe ao levantamento do que se sabe, mas significa explorar a questão de como se sabe e conhecer os caminhos que dão acesso a esses saberes. Se a discussão de temas como territorialidade, economia, religião, parentesco e noção de pessoa tem exigido uma atenção à importância que os Guarani dão à mobilidade e, com isso, à busca produtiva de lugares e relações, a transmissão de conhecimentos e a aprendizagem também podem ser abordadas como processos de deslocamento e comunicação entre espaços e interlocutores diferentes. Com isso, subverte-se o que encontramos em boa parte das etnografias sobre os Guarani Mbya, pois em vez de fazer um inventário dos modos de vida ou dos saberes como conjunto de características e produtos culturais, acompanha-se a realização dos processos de conhecer, levando a sério a idéia freqüentemente repetida pelos Mbya de que a vida de cada um é seu caminho de buscar e aprender.

1.As citações de pessoas Guarani Mbya são seguidas pelo nome, aldeia e ano de registro de cada fala. 
Desde a década de 1950, difundiu-se na literatura a divisão dos Guarani em três subgrupos: Kaiova, Mbya e Nhandeva. Segundo Schaden (1962), tal divisão se justificaria por diferenças lingüísticas e culturais, mas a maioria dos Guarani usa como autodenominação Nhandeva (nossa gente). Atualmente, há aproximadamente 30 mil Guarani no Brasil, sendo cerca de 6 mil Mbya.

Sob abordagens diferentes, os processos de produção, aquisição e transmissão de conhecimento permeiam boa parte da literatura sobre os Guarani, embora raramente sejam o tema central. Textos que datam do início do século passado até a produção mais recente oferecem múltiplas pistas para se caminhar pelas noções de conhecimento paralelas ou subjacentes às outras prioridades adotadas pelos autores na construção de suas descrições e argumentação. À luz disso e reconhecendo que a educação não pode ser desvinculada do seu contexto de realização e dos seus protagonistas, convém apresentar uma síntese dessa literatura, retomando a proposta de cada texto e suas possíveis contribuições para o entendimento do tema em foco.

De Nimuendajú (1987)[1914] até meados da década de 1970, os Guarani apareceram na literatura vinculados, sobretudo, à problemática da aculturação (Nimuendaju, 1954; 1987; Cadogan, 1960; 1967/68; Schaden, 1962; 1964; 1974). Trata-se de uma abordagem que apresenta inventários da "cultura" guarani como conjunto de características em processo de perda ou descreve a organização social enfatizando o contato interétnico como fator de desintegração. Dos autores desse período, os textos de Egon Schaden são bastante ilustrativos dos pressupostos e desdobramentos dos estudos da aculturação.

Num texto sobre a educação entre diversos povos indígenas, Schaden (1974) apresenta uma síntese clara dos pressupostos que orientaram seus trabalhos e o de colegas do mesmo período:

Dispersos pelo território em pequenos grupos mais ou menos autônomos e isolados, vivendo em íntima associação com a natureza, possuindo uma tecnologia bastante rudimentar e ignorando o uso de metais e de qualquer sistema de escrita, as nossas populações aborígines têm culturas relativamente rígidas e estáveis. 0 apego à tradição constitui freio constante às inovações e mudanças. A idéia de progresso não existe. Os objetivos de vida, de há muito bem definidos, não deixam lugar para dúvida e garantem a segurança de atitudes. (p. 9)

A definição que Schaden oferece de tradição em oposição à inovação é esclarecedora quando procuramos entender sua opção por tomar os Guarani como foco privilegiado de estudo dos impactos aculturativos do contato interétnico. Ao enfatizar um conjunto de características e elementos culturais em detrimento de uma abordagem que considera os processos de transmissão de conhecimentos, relações, objetos e substâncias como tradicionais, Schaden não podia compreender que para os Guarani relacionar-se com o Outro, seja este indígena, nãoindígena, humano ou não-humano, está no cerne das suas tradições. Em outros termos, a abordagem da aculturação impede a percepção de que a alteridade é motor das tradições.

Por outro lado, no estudo da organização social guarani, Schaden (1962) concebe cada aldeia como uma unidade, onde a fragmentação dos grupos que constituiriam essa unidade ideal é tomada como sinal de desintegração causada pelo contato com a sociedade não indígena. Ladeira (1992; 2001) e Pissolato (2006), no entanto, percebem a formação de grupos de parentes e a eventual cisão de um grupo em relação a outro, que pode resultar na constituição de um novo tekoa ${ }^{2}$ no interior de uma mesma terra indígena ou em outro local, como característica da organização social mbya, para a qual a dinâmica fluida das relações é altamente produtiva.

2. 0 termo tekoa é freqüentemente reduzido como equivalente de aldeia. No entanto, tomando-o como substantivo constituído por teko, conceito que remete a um modo próprio de viver num mundo de relações, onde é possível usar o termo para se referir inclusive ao modo de viver próprio de vários seres não-humanos, percebe-se que o tekoa não se refere aos limites de uma aldeia, mas indica um espaço onde se tecem relações entre parentes de um grupo local. 
A noção de pessoa é central às concepções guarani acerca da produção, transmissão e aquisição de conhecimento (Schaden, 1974; Ladeira, 1992; Pissolato, 2006; Testa, 2007). Para Schaden (1974), a noção de pessoa guarani está centrada numa "teoria das almas" (p. 11), segundo a qual cada indivíduo portaria duas almas. No caso dos Mbya, Pissolato (2006) descreve duas almas: ã e nheë. A primeira está ligada ao corpo e é freqüentemente associada à sombra da pessoa, enquanto o nheë, às vezes denominado ayvu, também significa fala e é central ao conhecimento na medida em que possibilita a comunicação. Cadogan (1960) associa a capacidade de comunicação à interlocução que se mantém com os deuses, na medida em que estes fazem circular palavras entre quem se lembra deles e com eles se comunica. Testa (2007) sugere que o papel do nheë nos processos de conhecimento está associado à idéia de mobilidade, -guatá (caminhar), pois ao caminhar e se relacionar entre perspectivas diferentes, humanas e não-humanas, o nheë exerce sua capacidade de adquirir e transmitir conhecimento e poderes.

Em relação à origem e ao destino do nheë ou ayvu, os autores aqui citados são unânimes em afirmar que eventualmente voltam às regiões celestes de onde partiram, mas as reflexões que derivam disso, no que tange ao conhecimento, são diversas.

Schaden $(1962 ; 1974)$ enfatiza que os Guarani dos três subgrupos descrêem da eficácia de quaisquer medidas pedagógicas para a formação da pessoa, investindo toda sua energia em "medidas e precauções de natureza mágica" (1974, p. 11). Ao descrever tais medidas e precauções, ele inclui a série de cuidados tomados pelos pais que acompanham a gestação até os primeiros anos de uma criança e que podem se estender a todos os parentes próximos e, por outro lado, os rituais que se destinam a "controlar o desequilíbrio" provocado por acontecimentos individuais ou coletivos, como nascimentos, doenças, mortes, viagens etc. (1962, p. 85).

Pissolato (2006), no entanto, sugere que é justamente nesses cuidados e nas práticas xamanísticas de produção de parentesco que reside a produção de conhecimento, ou seja, como Testa (2007) propôs, a não ser que insistamos em reduzir o conhecimento à educação escolar, os processos de produção, aquisição e transmissão de conhecimento estão no centro do cotidiano guarani de caminhar entre e se relacionar com parentes, outros humanos e não-humanos, evidenciando o exercício dessas almas em comunicação e deslocamento.

A partir da década de 1970, contrapondo-se às abordagens da aculturação até então predominantes no âmbito dos estudos sobre os Guarani, Hélène Clastres (1978) destaca a necessidade de prestar atenção aos discursos destes para compreender a importância e os significados que atribuem a diferentes aspectos da cosmologia e do cotidiano. A partir disso e baseando-se nos relatos dos cronistas acerca dos antigos Tupi e Guarani, Clastres pôde aproximarse de uma abordagem que enfatiza a continuidade em vez de ruptura, mudanças e perdas.

Considerando que as palavras para os Mbya têm sentido, no duplo entendimento do termo, revelando significados e também possuindo origem e direção, tornando-as potencialmente produtivas de saberes e ações, a proposta de seguir as palavras dos Guarani na compreensão dos seus significados e percursos é fundamental à investigação das trajetórias de produção, transmissão e aquisição de saberes.

Nesse sentido, percebe-se que muitos discursos remetem a uma associação entre conhecimento e fortalecimento. Os Mbya dizem que quem tem conhecimento saberá e conseguirá se fortalecer e estender os benefícios disso para além do seu grupo de parentes. Os discursos guarani sobre a destruição da Terra, mencionados por Clastres (1978), Nimuendaju (1987) e Ladeira (1992; 2001), podem ser entendidos nesse contexto, pois embora a vida nessa Terra seja insatisfatória - imagem imperfeita e corruptível do mundo divino -, os Guarani se esforçam por fazê-la durar, seja a existência de cada pessoa ou mesmo a continuidade desse planeta face à sua inevitável destruição. 
Pissolato (2006) afirma que o tema da cataclismologia não tem entre os Mbya o mesmo relevo encontrado em outros grupos guarani, sugerindo que a preocupação não se centraria na continuidade de existência dessa Terra em si, mas no envio contínuo, por parte das divindades, de almas e saberes que permitam a continuidade dos Mbya. Meus próprios dados, no entanto, apontam para uma relação maior entre a existência dessa Terra, o envio contínuo de almas e esforços para a produção de pessoas mbya. llustrativa desse ponto é a afirmação comum entre os Mbya de que esse mundo deixará de existir quando os deuses deixarem de enviar almas mbya ou quando os mbya não conseguirem mais ouvir e ser ouvidos pelos deuses.

Para Pissolato (2006), a idéia dessa Terra e dos atuais Mbya serem imagens daquela humanidade divinizada dos primeiros tempos está relacionada à possibilidade de manter uma comunicação contínua com as divindades, recebendo, destas, forças e saberes existenciais. Nesse sentido, se essa Terra está fadada a perecer, a continuidade de vida nela expressa o vínculo com os imortais.

Por ora, interessa reconhecer que a produção dessa continuidade se articula à produção, aquisição e transmissão de saberes. No entanto, não se tratam de quaisquer saberes. Por serem enviados pelas divindades imortais, são uma espécie de sabedoria infinita, aquela cuja trajetória de transmissão não se interrompe. É nesse sentido que os Mbya podem conceber uma distinção entre os conhecimentos escolares, principalmente informações impressas nos livros e os conhecimentos que se adquirem por comunicação com os deuses ou que se conhecem por meio das palavras de outras pessoas.

No sentido de contribuir para o aprofundamento dessas questões, proponho que a aquisição e a transmissão de conhecimento estão atreladas à comunicação que se desenvolve, no eixo vertical, entre humanos e deuses e, no eixo horizontal, dos humanos entre si, sugerindo que parte importante do processo de conhecer se si- tua num universo de comunicação compartilhada. No caso do xamanismo, esse aspecto é particularmente enfatizado: sejam palavras dirigidas aos deuses no intuito de adquirir conhecimento e capacidades ou aquelas que buscam persuadir uma alma de uma pessoa doente a permanecer. 0 que está em questão é a habilidade de proferir as ayvu porã ("belas palavras"), que possibilitam ouvir as mensagens divinas e ser escutado. Tomo, como exemplo disso, a fala de um xamã mbya que havia acabado de tratar uma criança pequena que sempre adoecia:

Eu conversei com a alma dela. Ela não quis mais ficar porque já viu muita tristeza aqui na terra. Parece só uma criança, mas sua alma sabe tudo que acontece e ficou triste com os parentes. Aquela alma não vai mais ficar, já foi embora. Por isso eu pedi para os deuses mandarem outra alma para ela e agora o nome dela mudou. (Karaí Tataendy, Tekoa Ytu, 2006)

Se a transmissão de conhecimento envolve o esforço para se comunicar, indicando o fluxo contínuo de saberes que se adquirem de uma exterioridade divina, vinculada aos Mbya por uma linguagem que os deuses compartilham com eles, desde o envio de almas-nomes que se tornam meio privilegiado de comunicação e interpretação de saberes-poderes, não se ignora o papel do conhecimento nas relações que se travam com outra exterioridade, povoada por subjetividades às quais se procura negar a possibilidade de comunicação.

Assim, os saberes e as forças adquiridos na comunicação com os deuses são canalizados para lidar com essa exterioridade perigosa, tema cuja discussão assume diferentes formas entre os Mbya, conforme avaliam seu contexto de enunciação. Nesse sentido, quando se dirigem a platéias não indígenas, freqüentemente incorporam às suas falas elementos de um contexto discursivo ambientalista, apropriando-se de noções que atribuem aos povos indígenas um tipo específico de relação com a natureza. Nesses 
casos, podem se apresentar como "protetores" da natureza e contribuir para reforçar a idéia de que povos indígenas vivem em harmonia com ela. No entanto, quando falam entre si, a natureza é povoada por seres que representam a alteridade em relação aos humanos, relação essa que pode ser contrária às ações e aos interesses dos humanos. Nesses casos, a natureza se revela nos discursos não como uma extensão harmônica da vida guarani, mas como local de negociação e também agressão.

A escolha contextual de discursos e conhecimentos a serem comunicados pode ser compreendida como aspecto relacionado à gestão do conhecimento. Para Simon Harrison (1995), o conhecimento pode ser concebido como recurso cujos processos de produção, aquisição e transmissão são culturalmente construídos de acordo com o valor e o significado que é atribuído a esse conhecimento. Sua discussão se centra na circulação do conhecimento, enfatizando que a valorização deste pode estar atrelada à sua circulação ampla ou a restrições que o tornam acessível a poucos. Entretanto, em vez de tratá-las como alternativas polares, Harrison afirma que em cada contexto há uma combinação específica de ambas as estratégias.

Considerando a gestão de conhecimento entre os Mbya, sugiro que a ênfase está nos caminhos de acesso ao conhecimento. Assim, mais do que possuir os conhecimentos, os Mbya se preocupam em se apropriar de um conhecimento cuja autoria e "propriedade" situam-se numa exterioridade. Isso parece ir de encontro com o que Manuela Carneiro da $\mathrm{Cu}$ nha (2004) observa na etnologia amazônica, na qual se percebe que o conhecimento é concebido como "empréstimo" que é incorporado, tendo sua origem numa exterioridade.

No mesmo sentido, Dominique Gallois (1996) fala que, no caso waiãpi, os cantos são um elemento relacional, nos quais o xamã transmite as palavras dos outros e, assim, o que está em foco não é a posse dos cantos ou palavras, mas a aquisição do acesso à comunicação com diferentes domínios.
Extremamente reservados sobre seus cantos, os xamãs afirmam terem cantos próprios. 0 que é privativo, na verdade, é menos a canção propriamente dita que a comunicação com algum domínio sobrenatural que o canto representa. 0 canto é assim a emanação de uma relação, construída durante a iniciação, transmitindo a palavra das entidades paie. (p. 67)

No caso dos Mbya, é no reconhecimento de uma fonte de autoria externa que a fala apresentada a seguir enfatiza as precauções que devem ser tomadas na transmissão de conhecimentos.

Nós temos que ter muito cuidado com o que uma pessoa conta para nós, porque essa voz que fala não é da pessoa, mas de Nhanderu [Deus], então tem que ter muito respeito pelas palavras que vêm desse outro mundo, e só pode contá-las para quem também vai ter esse respeito. Às vezes, a gente fala uma coisa que vai ser muito importante para a pessoa e para sua vida, mas ela não entende ou não sabe para o que ela vai usar esse conhecimento. É como a própria mão; ela é feita por Nhanderu e qualquer coisa que a pessoa quiser fazer de bom com a mão, ela vai conseguir, porque Nhanderu vai dar força, mas a mão também tem a força para fazer mal e até destruir as coisas que o próprio Nhanderu criou. É a mesma coisa com o conhecimento, ele pode ser usado para fazer o bem ou o mal. É por isso que quando xeramoi vai ensinar alguma coisa ele primeiro pede para Nhanderu para saber se ele pode revelar esse conhecimento. (Tupã Mirim, Tekoá Pyaú, 2004)

Fica clara aqui a noção de que as pessoas não possuem definitivamente os conhecimentos que adquirem, antes as acessam continuamente para colocá-los em circulação. Assim, é prestigiado não aquele que possui muito conhecimento, mas aquele que demonstra a capacidade de acessá-lo e mobilizá-lo, seja na cura, na liderança de um grupo ou no aconselhamento. Sua distribuição é 
valorizada não apenas na condição de disponibilizar muitos conhecimentos continuamente, mas também de saber restringir sua circulação entre aqueles que saberiam aproveitá-los. É nesse sentido que os xamãs podem deixar de identificar publicamente as origens de determinadas agressões ou salientam a necessidade de não compartilhar certos conhecimentos com pessoas não indígenas ou mesmo com parentes. Nesse contexto, a ênfase não está numa noção de propriedade em si, mas sobre suas condições de uso.

Por outro lado, o conhecimento adquirido por experiência própria também é valorizado pelos Mbya. Como Carneiro da Cunha (2004) aponta para vários povos ameríndios, entre os quais eu sugiro incluir os Mbya, os critérios de valorização e veracidade do conhecimento estão associados a uma experiência que se viveu pessoalmente. Assim, quando se aceita que cada pajé tenha seu próprio estilo, coloca-se em pauta a idéia de que o conhecimento adquirido e mobilizado por cada um deles é fruto de uma experiência pessoal de comunicação com os deuses, construída por meio de uma vivência individual. 0 que para Carneiro da Cunha estaria associado à idéia de que "ver" ou "ouvir" não são dados, mas demandam uma aprendizagem. Portanto, aquele que conta porque viu ou ouviu algo pessoalmente evidencia ter adquirido o saber-poder que possibilita tal experiência.

Eu sugiro, portanto, que o conhecimento xamanístico, associado à comunicação, está relacionado aos sentidos e à importância que se lhes atribui, aspecto pouco tratado na literatura sobre os Mbya, mas recorrente nas elaborações mbya sobre o xamanismo, quando afirmam que o xamã é aquele que "vê" o movimento e o tempo das coisas e seres ou aquele que "ouve" as mensagens dos deuses.

A pessoa que faz essa cura, ela vê o movimento e a velocidade das coisas. Por isso, quando ela vai consultar uma pessoa que está doente, ela pega o petÿguá [cachimbo] e fica fazendo seu trabalho só com Nhanderu. Só ela e Nhanderu. Nesse momento, ela começa a ver tudo que está em volta: o solo, as árvores, as cachoeiras e várias outras coisas. [...] Se você pensar nisso tudo, você vai perceber que está num espaço muito pequeno do mundo e ele é feito de muitas coisas que você não consegue enxergar, por isso você nunca sabe onde vai pisar. Muita gente não acredita nessas coisas porque não consegue enxergá-las, e as pessoas só acreditam naquilo que vêem. 0 tijolo a gente vê, você mesma está vendo este chão, mas não está vendo o que está além dele. Na verdade, você não está vendo nada mais do que o chão. É por isso que as pessoas não acreditam, mas eu acredito porque nhanheramoi [nosso xamã] fala que é assim e você sabe que o que eles dizem acontece mesmo. É assim que as doenças são vistas pelo médico guarani. A kunhã karaí [mulher xamã] consegue ver o efeito das coisas acontecendo. Ela consegue ver os espíritos das coisas que atingiram a pessoa doente. (Verá Nhamandu Mirim, Parati Mirim, 2005)

Tendo em vista que o processo de transmissão de conhecimento é relacional, considera-se também a experiência daquele que o adquire e o ponto de vista a partir do qual ele interpretará os conhecimentos. Nesse sentido, há uma tentativa, como no caso das situações de aconselhamento, de falar pautando-se nas suas próprias experiências de vida e na interpretação que se faz das experiências narradas por aquele a quem os conselhos se dirigem. Num trabalho anterior (Testa, 2007), procurei entender a comunicação como situação em que se procura aproximar-se do ponto de vista do outro. Essa aproximação que permitiria aos interlocutores situarem-se no mesmo universo de linguagem compartilhada pode ser interpretada como forma de administrar os desdobramentos que os conhecimentos e as palavras têm a partir da sua transmissão.

É nesse sentido que entendo as afirmações dos Mbya quando indicam os cuidados que se deve ter na escolha dos conhecimentos 
disponibilizados para diferentes pessoas, pois se dizem que a palavra pronunciada adequadamente pode entrar no outro e servir como remédio, também dizem que a palavra que se perde no meio do caminho entre interlocutores ou que toma um sentido "desviado" pode trazer prejuizos, inclusive para aquele que a pronunciou. Dentre os prejuízos citados, estão: os conflitos que afloram quando um xamã revela o agente responsável por alguma agressão, a doença, o enfraquecimento ou a perda de capacidades xamanísticas que um xamã pode experimentar caso suas palavras sejam apropriadas por outros de forma inadequada ou sejam reveladas a pessoas que não deveriam ter acesso a elas.

\begin{abstract}
A palavra tem que entrar e ficar no coração ou no pensamento da outra pessoa. Quando o xeramoi ou eu mesmo falamos é também um remédio. Se uma pessoa está triste ou preocupada, nossa palavra serve para tratar a pessoa, mas se a pessoa não quer ouvir, isso volta para nós mesmos e faz mal. (Karaí Tataendy, Tekoá Ytu, 2007)
\end{abstract}

Tendo em vista o objetivo de abordar a transmissão de conhecimento e a aprendizagem como processos de comunicação e deslocamento entre espaços e interlocutores, passo agora a tratar desse segundo aspecto que coloca em foco a noção de que o conhecimento é apreendido na disposição de estar atento às experiências que se tem nos caminhos percorridos.

Um colaborador mbya de Schaden (1962) certa vez destacou: "Sem caminho, não se chega ao lugar que se pretende alcançar” (p. 173). Sugiro que essa afirmação pode ser compreendida no duplo sentido que tem a mobilidade para os Mbya: no deslocamento físico e no trabalho de deslocamento que têm as almas (nhe'ë) nos caminhos de acesso à comunicação entre humanos e deuses. Essas duas formas de entendimento da mobilidade são complementares, assim como é dialética a relação entre conhecimento e caminho, no sentido de que se o caminho é condição para a aquisição de conhecimentos disponibilizados pelos deuses ou oriundos da própria vivência, o conhecimento também é condição para se fazer o caminho, na medida em que é necessário saber distinguir, evitar ou suportar obstáculos que podem ser encontrados no meio do percurso.

Nesse sentido, sugiro que o nhe'ë pode caminhar em diversos sentidos e circunstâncias, seja na reza e nos cantos quando se comunica com os deuses e acessa os conhecimentos por eles disponibilizados, seja nos sonhos em que é possível receber visitas e conhecimentos de outras almas ou colocar-se em movimento visitando parentes, regiões distantes ou mesmo a morada de Nhanderu, ou na conversação entre almas que, conforme os Mbya indicam, exige por si uma complexa transação entre palavras-almas que fluem entre os eixos vertical e horizontal.

Enfim, o que está em pauta quando se trata do conhecimento são os caminhos que mobilizam corpos, almas e relações, e talvez seja por isso que os Mbya falem constantemente em "alcançar" e "achar" quando tratam da aquisição de saberes e capacidades. Nesse sentido, se não usam o verbo "fazer" para falar do conhecimento, minha hipótese é de que a produção de conhecimento não é problematizada com a mesma ênfase com que são sua aquisição e transmissão, justamente porque a autoria de grande parte do conhecimento se situa numa exterioridade, cabendo aos humanos investir nas suas vias de acesso. Em consonância com isso, em vez de tomar o conhecimento como objeto produzido a ser adquirido, acumulado e transmitido, entender o conhecimento como rede de caminhos que articulam pessoas, deuses e outras subjetividades permite realizar uma pesquisa focada nos processos de conhecer e não necessariamente presa a um inventário do que é conhecido.

\section{Oralidade e escrita nos caminhos do conhecimento}

Tomando como ponto de partida a questão: Quais os sentidos da educação escolar indígena nos contextos múltiplos de produ- 
ção, aquisição e transmissão de saberes desenvolvidos pelos Guarani Mbya?, é possível pensar as relações entre oralidade e escrita na educação (escolar) indígena sem cair automaticamente nas armadilhas de pressupostos universais. Portanto, ao abordar essa questão, procuro articular algumas ponderações registradas nesses anos de pesquisa e convivência com os Mbya a um conjunto de leituras para explorar (sem a pretensão de esgotar) certos paradoxos que a educação escolar indígena nos apresenta.

Maurício Gnerre (1987) afirma que as relações entre escrita e sociedade se tornaram objeto de estudo sistemático em meados do século XVIl, quando o confronto de europeus com o que eles percebiam como "povos sem escrita" gerou formas de pensar essa diferença como deficiência, estabelecendo-se uma espécie de linha imaginária, evolutiva e progressiva na qual situavam diversas sociedades segundo a utilização ou não da escrita alfabética.

Por outro lado, o contato de povos indígenas no Brasil com a escrita nos leva a percorrer outros percursos de reflexão. A fala de Verá Mirim na abertura deste artigo desloca a relação entre escrita e memória, sugerindo que, em vez de preservar a memória, a escrita se perde, enquanto as palavras suspiradas no interior de cada um e distribuídas coletivamente se mantêm nos caminhos de circular conhecimentos.

Para retomar sua fala, é importante lembrar a importância que a palavra-falada-cantada tem para os Guarani, a começar pela concepção de que o termo nhë'é se refere simultaneamente à palavra e à alma. Assim, a palavra assume um papel privilegiado no universo de relações, colocando-se como elemento que serve para unir ou separar, igualar ou distinguir pessoas e perspectivas.

Por outro lado, essa associação entre palavra e alma traz consigo a idéia de que, nas trocas entre interlocutores, as palavras-almas que passam entre narrador e ouvinte não se limitam a sons depositários de sentidos. Mais do que uma situação de expressão verbal, por meio da narração das suas próprias experiênci- as de vida, o narrador doa ou empresta algo que lhe constitui, por isso, receber suas palavras é relacionar-se, não apenas com o interlocutor e todos os saberes e as experiências que o constituem, mas também percorrer as perspectivas que ele acessa para receber ou produzir esses saberes.

Nesse sentido, podemos, como Menezes de Souza (2006) sugere, pensar o saber como perspectiva (alguém só conhece aquilo que vê e a partir de onde vê). Assim, na relação de ensino-aprendizagem, fica clara a necessidade de experimentar lugares diferentes, sejam perspectivas ou deslocamentos. 0 xamã se aproxima dos deuses para aprender os caminhos que deverá seguir e as orientações que deverá transmitir aos companheiros. Seja no sonho ou na reza, sua capacidade de aprender e ensinar dependem de um trabalho de deslocamento e tradução, de um caminhar flutuante e fluente entre perspectivas e interlocutores diferentes.

Conceber os processos de conhecimento como relação não deixa de suscitar os perigos que caminhar entre os meandros da alteridade evoca. Esse problema é abordado pelos Guarani quando falam não apenas dos perigos enfrentados no acesso ao conhecimento, mas também do perigo de se expor como portador desse conhecimento, pois este se desloca entre possibilidades ou estados provisórios que não devem ser polarizados ou pensados separadamente.

Quando os juruá vêm aqui perguntar da nossa religião, não podemos dizer muito porque tem uma parte que é segredo e se falarmos disso, o próprio Nhanderu castiga. Até um pajé não pode ficar falando que ele é pajé que é forte e tudo mais. Quando você tem sabedoria, você tem que pegar seu petÿguá e fumar, fazer sua reza, ter muito amor por todo mundo, mas não pode ficar contando o que sabe e o que faz, até mesmo para os parentes. Eu estou fazendo um treinamento com os mais velhos, mas é muito difícil para ser pajé. Não é todo mundo que consegue porque tem muita provação, 
até da própria comunidade tem provação, dizendo que aquele não é pajé, que não tem força, que é mentira. Alguém também pode fazer maldição contra você, então é muito difícil mesmo. Então, você tem que ter muito cuidado. Tem que pegar seu petÿguá e fazer sua reza para ter força, saúde e bastante vida. É por isso que estou vivo até hoje, porque faço minha reza e até meus parentes que estão longe também fazem sua reza, pedindo proteção para nós todos. (Içário, Aldeia do Tapixi, 2006)

A exposição até aqui de algumas considerações sobre o conhecimento nos permite explorar outra questão: nesse universo em que saber é necessariamente relação e não apenas expressão, qual o lugar das palavras escritas? Entretanto, antes de caminharmos por esse dilema, caberia retomar alguns dos pressupostos que colocamos em suspensão no início deste texto.

Grande parte dos estudos que se dedicam à discussão da oralidade e da escrita toma a escrita como central, demonstrando timidez na compreensão dos processos de transmissão oral (Goody, 1968; 1993; 1995; Vernant, 2002; Detienne, 1998). Embora tratem da escrita em contextos diferentes, a escrita é predominantemente percebida por esses autores como meio de formulação do pensamento abstrato, discursivo e crítico e de atribuir uma forma preservada, fixa ou congelada a idéias e conhecimentos. Considerando que tais estudos atribuem pesos desiguais à apreciação da oralidade e da escrita e que partem de lugares de enunciação embebidos pelas águas mornas da escrita alfabética, sua perspectiva da oralidade e da escrita não pode ser tomada como neutra ou universal. Deve-se, portanto, reconhecer esses lugares de enunciação (Bhabha, 1994) e a necessidade de conhecer e reconhecer outras perspectivas ou, como Chakrabarty (apud Menezes de Souza, 2006) sugere, provincializar as concepções ocidentais se quisermos ter acesso a outras formas de se pensar os processos de produção e consumo de conhecimentos.
Um passo nesse sentido seria prestar mais atenção não apenas ao que os índios dizem sobre suas tradições orais, mas também às suas reflexões sobre a escrita, de modo a não reproduzir a dicotomia "povos com escrita/ povos sem escrita" sob o disfarce de "antropólogos, pedagogos ou lingüistas que falam da escrita/indios que apresentam seus conhecimentos orais para serem registrados em escrita”.

Considerando isso, quando iniciei o trabalho de campo na aldeia de Parati Mirim, um dos professores guarani, ao tomar meu projeto de pesquisa em suas mãos, confrontou-me com o seguinte problema:

Tem muita coisa escrita aqui, mas quem é que entende tudo isso? A gente precisa escrever menos e entender mais. Nós já estamos fazendo a nossa parte, fazendo um esforço enorme para escrever projetos e entender todos esses documentos escritos. Quando é que vocês vão fazer sua parte: aprender nossa língua e aquilo que é falado e não apenas aquilo que vocês lêem? Quando é que vocês juruá vão preparar seus ouvidos e corações para entender as palavras dos mais velhos? (Verá Nhamandu Mirim, Parati Mirim, 2004)

Na medida em que seu contato com os cursos de magistério e os conflitos na aldeia sobre o papel da escola intensificavam, Verá Nhamandu Mirim confrontava todos com a ambivalência que ele detectava nas relações entre oralidade, escrita, xamanismo, escola, política indigenista e política guarani. Ou meIhor, ele se posicionava diante de seus interlocutores guarani ou não-indígenas partindo de lugares de enunciação diferentes e marcados por ambigüidade, seja como professor, secretário da Associação da sua aldeia ou participante dos saberes e fazeres xamanísticos.

Nesse sentido, ao se deparar com a reclamação das outras lideranças de que uma escola boa é igual à escola dos não-indígenas, inclusive com professores não indígenas, pois muitos esperavam que a escola fosse um espa- 
ço para aprender os conhecimentos dos nãoindígenas e não um espaço para "aprender a ser Guarani”, Verá Nhamandu Mirim recolocou o problema, associando a educação ao conhecimento xamanístico: "Se esses funcionários da Secretaria de Educação ou da Funai têm tanto conhecimento assim, por que vocês não pedem para eles virem na opy [casa de rezas] fazerem reza quando vocês estão doentes?".

Essa questão inquietante traz à tona dois pontos fundamentais: os conflitos entre lideranças e a participação (freqüentemente estratégica) de funcionários indigenistas nessas situações e, por outro lado, a concepção de que o conhecimento não se dissocia de uma teoria guarani de entendimento, isto é, de que o conhecimento e sua eficácia se produzem nas relações entre parentes, deuses e outras subjetividades. Assim sendo, os funcionários não indígenas teriam acesso a apenas uma parcela dessas relações e saberes, já que se excluem das redes de parentesco e da religiosidade guarani.

Portanto, o que parece estar em jogo não é apenas a exposição de diferentes visões de mundo, mas o entendimento do que é o conhecimento propriamente dito e os caminhos para a aquisição deste. Quando Verá Nhamandu Mirim pede para as lideranças pensarem se chamariam os funcionários da Secretaria de Educação ou da Funai para cuidar dos doentes na casa de rezas, ele não está preocupado apenas em delimitar o campo de atuação deles, mas coloca em xeque a confiança que as lideranças depositam nos conhecimentos especializados desses agentes, reafirmando que o conhecimento guarani está associado ao xamanismo e que a capacidade xamânica se revela por meio de uma "visão" que possibilita o acesso a seres invisíveis e a capacidade de se comunicá-los, manipulá-los ou afastálos para orientar, proteger e curar as pessoas.

Como ele enfatiza, esse não é um conhecimento acessível aos não-indígenas nem a todos os Guarani. 0 que nos leva a perceber que o conhecimento não é igual para todos ou, em outras palavras, se conhecer é ver, como Menezes de Souza (2006) sugere, o que uma pessoa "sabe- vê" pode não ser igual ao conhecimento-visão de outra pessoa, porque ambos vêem-conhecem de lugares e perspectivas diferentes.

Eu acho que deve ser difícil para o juruá entender isso... eu não sei se um dia ele vai chegar a entender isso. É uma coisa que até para nós Guarani é um mistério que a gente não revela, a gente não vê. Só a pessoa que tem a capacidade consegue ver e dizer isso. Eu mesmo faço parte da comunidade e tenho minha reza que eu faço na opy, mas eu não sou curador, então, eu não posso jamais chegar para alguém e dizer que sou. (Verá Nhamandu Mirim, Aldeia Parati Mirim, 2005)

Nesse contexto em que o conhecimento se constrói como perspectiva e relação, a palavra escrita traz certo paradoxo, pois a multiplicação de textos em língua guarani ou português, estimulada pelas políticas oficiais de educação escolar indígena nem sempre encontra ressonância nos discursos guarani. Poderíamos até dizer que para muitos Guarani a escrita não é uma forma de registrar ou "representar" suas palavras (almas) faladas e que as formas guarani de conceber o conhecimento colocam certo pressuposto de universalidade do uso e da significação da escrita em cheque. Para ilustrar esse ponto, voltemos às palavras de Verá Nhamandu Mirim:

Um dos professores da aldeia falou para os evangélicos que não precisava de uma Bíblia porque seu petÿguá era seu livro, é dele que vêm as palavras de Nhanderu; é através dele que a pessoa conversa com Nhanderu e recebe seus conhecimentos. Para nós é assim: quando você pega o petÿguá, você está parando naquele momento para você pensar, você está trazendo algo diferente para dentro de você. É bem diferente de ficar com um livro na mão estudando porque com o petÿguá você tem a liberdade de falar o que você sente, naquela hora você tem liberdade!

Se você tiver fé mesmo e acreditar em 
Nhanderu, a casa de reza está lá, a hora que você quiser, você pode ir lá. É assim, ninguém vai impor regras do que você tem que falar, você vai falar tudo que tiver que falar... para Nhanderu. Então, o petÿguá é como se fosse um livro do jeito guarani, só que é diferente de um livro, é claro. Não tem nenhum mistério. Eu fiz essa comparação porque com o livro, você tem que aprender o que está no livro e não o que você sente e quer falar, então na minha religião, eu não quero um livro, eu quero conversar com Nhanderu, não com um livro. (Verá Nhamandu Mirim, aldeia de Parati Mirim, 2005)

Se o livro é percebido como limitado no registro e na transmissão de saberes, deparamo-nos com outro desencontro entre os pressupostos que nutrem as políticas oficiais de educação escolar indígena e as formas guarani de pensar a relação entre conhecimento e a língua materna. Em outros termos, a idéia de que o registro escrito e a gramatização de uma língua serviriam para “preservá-la” é incomensurável com algumas concepções guarani, o que transparece no desejo de muitos de que sua língua não seja ensinada na escola ou nos livros. No entanto, essa questão não está fechada, pois existe muita disputa em torno do papel da escola nas aldeias guarani.

Sugiro que uma possibilidade para explorar os diferentes aspectos dessa disputa seria caminhar entre as palavras de alguns protagonistas das escolas guarani, reconhecendo que, mesmo diante da complexidade que suas opiniões colocam, elas certamente não esgotam todas as perspectivas e lugares de enunciação envolvidos nesse conflito.

Por exemplo, teve uma reunião em que uma das lideranças queria que as crianças tivessem aula só em português, mas ela não é a única que pensa assim. Muitas lideranças querem que as crianças tenham só português, matemática, história e outras matérias iguais à escola juruá. Enquanto eu, como educadora, quero trazer a tradição, quero trazer a cultura e essas coisas para a sala de aula. Então, a gente fica sempre nesse conflito. (Poty Poran, Aldeia Tekoá Ytu, 2004 )

Está claro para essa professora que suas opiniões se formaram num conjunto de experiências que ela compartilha com outros professores guarani que, como ela, são jovens lideranças escolarizadas que aderem, em grande medida, à concepção, freqüentemente defendida pelos movimentos indígenas, de uma educação escolar indígena específica e diferenciada, na qual a escola é um espaço permeado pelos conhecimentos e meios de aprendizagem guarani:

Se você pensar bem, a maioria dos professores, pelos menos aqueles com quem tenho contato, inclusive de outras aldeias, pensa como eu. Eles querem trazer a tradição, a cultura, a visão de mundo guarani para dentro da escola. A gente quer trabalhar a língua guarani, a gente quer trabalhar a matemática guarani, a gente quer trabalhar com as brinca-deiras guarani, a gente quer reforçar a cultura. (Poty Poran, Aldeia Tekoá Ytu, 2004)

É nesse sentido que ela pensa a alfabetização em língua indígena como forma de valorização da língua materna, pois a influência da escrita é tão significativa, a seu ver, que a língua em que se aprende a escrever pode ganhar uma importância considerável na vida das pessoas.

[...] eu acho que se a criança aprender a escrever primeiro em guarani, ela vai ter mais orgulho da língua dela e vai ter menos perigo de perder essa língua, porque a gente sabe que quando o pessoal é alfabetizado numa língua estrangeira, aquela língua estrangeira acaba se tornando mais importante do que a língua materna, já que é a língua escrita. (Poty Poran, Aldeia Tekoá Ytu, 2004)

Por outro lado, o esforço para compreender a opinião das outras lideranças de que "escola boa é escola igual à escola dos juruá", 
fez com que essa professora se deparasse com a concepção de que a língua está diretamente associada à alma e ser Guarani é ter alma guarani, o que significa falar guarani.

Numa reunião de pais, eu tive um insight: uma das lideranças falou assim: "As crianças nunca vão perder a língua guarani porque elas são Guarani" [...] eu fui para opy e fiquei pensando muito, me esforçando para entender o pensamento das outras pessoas. Aí, eu lembrei que na opy, o xamoi (xamã) sempre fala que në'é é nossa fala, mas também é nossa alma. [...] Então, se a alma é guarani, sua fala também é guarani, e quando a pessoa fala que quem é Guarani nunca vai perder a língua guarani é porque a pessoa não vai perder sua alma. (Poty Poran, Aldeia Tekoá Ytu, 2004)

Por outro lado, a escrita pensada como meio de preservação da língua é outro problema que permeia os discursos dos Guarani e de seus interlocutores não indígenas. Tomo como exemplo dessa questão alguns trechos da história de vida de Arlindo Tupã Veríssimo, professor guarani do Rio das Cobras, no Paraná, e colaborador do programa de educação escolar do Summer Institute of Linguistics (SIL), instituição missionária que atua há mais de vinte anos nesse estado. Essa instituição mantém uma proposta de evangelização em língua nativa que inclui a tradução e a impressão de textos bíblicos. Daí a ênfase que se dá a pesquisas lingüísticas e ao treinamento de nativos que possam traduzir, ler, escrever e dar continuidade ao trabalho missionário, tudo sustentado por um discurso que relaciona a escrita à sobrevivência de uma língua e de uma cultura (Hvalkof; Aaby, 1981).

No entanto, por outro lado, esse projeto missionário se coloca num espaço de confronto de diferentes lugares de enunciação (Bhabha, 1994), pois nos seus processos de construção de significados para a escrita e a escola, os Guarani deslocam o encaminhamento desse projeto, colocando- o num espaço movediço de conflito e disputa.

A história de vida do professor guarani Arlindo Tupã Veríssimo, principal colaborador do Missionário Robert Dooley (1982), expressa a força desses processos de elaboração de significados e experiência. Ele apresenta seu trabalho no SIL como um projeto de realização pessoal e meio para garantir os objetivos do seu grupo de parentes próximos, e não como um processo pelo qual ele foi treinado para dar continuidade às atividades do SIL.

Quando aprendi a escrever meu nome e fui aprendendo as palavras, eu fiquei maravilhado e queria estudar e aprender mais. [...] Eu queria mesmo trabalhar em pelo menos quatro ou cinco aldeias diferentes aqui no Paraná. Meu interesse era de pesquisar a língua mesmo, então o missionário gostou, concordou comigo e disse que era disso que eles precisavam. [...] Como eu falei, eu ia buscando pesquisa, buscando a língua em toda parte dos Guarani, então assim a gente conseguiu. [...] E foi nesse trabalho que eu pude realizar meu sonho de continuar estudando, fazendo essa pesquisa com a língua e a escrita guarani. (Arlindo Tupã Veríssimo, Aldeia Tapixi, 2006)

Na sua experiência de trabalhar na tradução da Bíblia e de outros textos para o guarani ou na elaboração de uma gramática guarani, ele não identifica uma contribuição que se restringe às iniciativas do empreendimento missionário, mas percebe essa trajetória como a construção do seu papel de professor, algo que lhe permite, inclusive, ocupar um lugar de destaque como liderança, não apenas em sua aldeia, mas na prefeitura local e nos seus contatos com professores guarani de outras regiões.

Eu já tinha esse interesse dentro de mim, já vinha 25 anos com esse sonho de trabalhar em cima da escritura, do escrito, e fazer um pequeno livro e cartilha para meu povo aprender. [...] Então, dá para ver que esse 
trabalho não começou há pouco tempo; ele já era pensado. Era meu interesse e o interesse de toda a comunidade também. E agora o município já está me reconhecendo e me nomearam para representante da educação indígena guarani aqui de Rio das Cobras. Isso facilita também para gente criar um pequeno livro ou uma cartilha que pode abranger todo o estado do Paraná. Pelo menos, foi isso o que eu pensei. Como eu tinha muito apoio do missionário, eu consegui tudo isso e agora deu certo. (Arlindo Tupã Veríssimo, Aldeia Tapixi, 2006)

A experiência de participar da elaboração de uma gramática em língua guarani tem um peso muito grande sobre a forma como esse professor pensa sua língua, algo que não coincide necessariamente com as outras perspectivas apresentadas até aqui.

Eu queria ficar um pouco de tempo em cada lugar para eu poder aprender as diferenças de dialeto de cada lugar e entender melhor a língua e a cultura. Foi assim que a gente criou até um dicionário, junto com a lingüística. A gente precisa sempre estudar junto com a lingüística para pegar as formas certas, para escrever as normas certas também, porque, imagine só, se eu escrevesse do jeito que eu estou falando, as normas não seriam corretas, não é verdade? Tudo isso a gente tem que estudar e entender primeiro para conseguir escrever a forma certa. E foi nesse trabalho que eu pude realizar meu sonho de continuar estudando, fazendo essa pesquisa com a língua e a escrita guarani. (Arlindo Tupã Veríssimo, Aldeia Tapixi, 2006)

A preocupação de Arlindo Tupã Veríssimo com a normatização da sua língua nos leva a lembrar que essa prática não é sem conseqüências. Gnerre (1987) aponta para uma relação direta entre a imposição de uma forma lingüística e práticas de dominação política e simbóli- ca. Ao descrever a expansão dos idiomas espanhol e português pelas colônias, ele recorre a registros do século XIV para demonstrar o quanto estava claro para alguns compiladores de gramáticas que a língua constituía arma eficaz no processo de conquista. 0 mesmo autor nos lembra da República platônica, onde uma versão do mito da nomeação originária se expressa por meio do legislador que escolhe e impõe ao mundo de objetos seus nomes apropriados.

Para Bakhtin (1979), a fixação gramatical de uma língua é ocupação dos "herdeiros e epígonos dominados pela palavra alheia que parou de ressoar". Por isso, segundo o mesmo autor, o processo de sistematização gramatical geralmente se restringe

[...] ao campo das línguas mortas e, ainda, somente nos casos em que essas línguas perderam, até certo ponto, sua influência e seu caráter autoritário sagrado. A reflexão lingüística de caráter formal-sistemático foi inevitavelmente coagida a adotar em relação às línguas vivas uma posição conservadora e acadêmica, isto é, a tratar a língua viva como se fosse algo acabado, o que implica uma atitude hostil em relação a todas as inovações lingüísticas. (p. 89)

\section{Conclusão}

Neste texto, procurei discutir a educação escolar indígena num contexto mais amplo e específico de produção, aquisição e transmissão de conhecimento, reconhecendo que uma compreensão densa desse contexto se faz fundamental quando se pretende tomar a escolarização indígena como objeto de reflexão e trabalho. Em se tratando das relações entre oralidade e escrita, além de um certo conhecimento acumulado acerca dos impactos sociais e históricos da escrita, o contato crescente de grupos indígenas com a escrita, principalmente nos programas de educação escolar, traz novos desafios e inquietações que são férteis não apenas para se pensar a oralidade e a escrita na educação indíge- 
na, como também para repensar os rumos que trilhamos nas escolas não indígenas.

As considerações apresentadas ao longo do artigo nos permitem observar que a educação escolar indígena não é um objeto, mas sim um processo em elaboração que envolve agentes e narradores cujas perspectivas não podem ser compreendidas se nos limitarmos a categorias estanques ou tomarmos certas categorias como se fossem universais. É possível perceber que, embora muitas das falas guarani neste tex- to indiquem a necessidade de pensar os processos de aquisição, produção e transmissão de conhecimentos a partir dos lugares que os interlocutores indígenas ocupam, esses lugares não são fixos ou únicos. Assim sendo, não podemos tratar a discussão sobre educação escolar indígena como se fosse uma mesa de debates na qual de cada lado haveria um "representante autorizado" de cada "unidade", afinal de contas e desde o princípio, o processo é mais complexo e híbrido.

\section{Referências bibliográficas}

BAKHTIN, M. Marxismo e filosofia da linguagem. Problemas fundamentais do método sociológico na ciência da linguagem. São Paulo: Hucitec, 1979.

BHABHA, H. K. The location of culture. London; New York: Routledge, 1994.

CADOGAN, L. En torno de la aculturación de los Mbya-Guarani del Guairá. América Indígena, XX, n. 2, México, 1960, p. 133150. 144 .

Chonó Kybwyrá: aves y almas en la mitologia guarani. Revista de Antropologia, XV/XVI, São Paulo, 1967/1968, p. 133-

CARNEIRO DA CUNHA, M. "Culture" and culture: traditional knowledge and intellectual rights. In: Marc Bloch conference (EHESS), 2004.

CLASTRES, H. Terra sem mal. São Paulo: Brasiliense, 1978.

DETIENNE, M. A invenção da mitologia. Rio de Janeiro: Jose Olympio, 1998.

DOOLEY, RA. Vocabulário do guarani: vocabulário básico do guarani contemporâneo (dialéto Mbüá do Brasil). Brasília: Summer Institute of Linguistics, 1982.

GALLOIS, D. T. Xamanismo waiãpi: nos caminhos invisíveis, a relação i-paie. In: LANGDON, E. J. M. Xamanismo no Brasil: novas perspectivas. Florianópolis: Ed. UFSC, 1996, p. 39-74.

GNERRE, M. Linguagem, escrita e poder. São Paulo: Martins Fontes, 1987.

GOODY, J. Literacy in traditional societies. Cambridge: Cambridge University Press, 1968.

. The interface between the written and the oral. Cambridge: Cambridge University Press, 1993.

The domestication of the savage mind. Cambridge: Cambridge University Press, 1995.

HARRISON, S. Anthropological perspectives on the management of knowledge. Anthropology Today, v. 11/5, 1995, p. 10-14.

HVALKOF, S.; AABY, P. (Orgs.). Is God an American? An anthropological perspective on the missionary work of the Summer Institute of Linguistics. Copenhagen; London: IWGIA/SI, 1981.

LADEIRA, M. I. 0 caminhar sob a luz. 1992. Dissertação (Mestrado)- Pontifícia Universidade Católica, São Paulo, 1992. 
Espaço geográfico Guarani-Mbya: significado, constituição e uso. 2001. Tese (Doutorado)- Faculdade de Filosofia, Letras e Ciências Humanas, Universidade de São Paulo, São Paulo, 2001.

MENEZES de SOUZA, L. M. T. Entering a culture quietly: writing and cultural survival in indigenous education in Brazil. In: MAKONI, S. PENNYCOOK, A. (Orgs.). Disinventing and reconstituting languages. Clevedon: Multilingual Matters, 2006, p. 135-169.

NIMUENDAJU, C. As lendas da criação e destruição do mundo como fundamentos da religião dos Apapocuva-Guarani. São Paulo: Hucitec, 1987.

. Apontamentos sobre os Guarani. Tradução de Egon Schaden. Revista do Museu Paulista, N. S., v. VIII, 1954.

PISSOLATO, E. de P. A duração da pessoa: mobilidade, parentesco e xamanismo mbya (guarani). 2006. Tese (Doutorado)- Museu Nacional, Universidade Federal do Rio de Janeiro, Rio de Janeiro, 2006.

SCHADEN, E. Aspectos fundamentais da cultura Guarani. São Paulo: Difusão Européia do Livro, 1962.

Aculturação indígena. Ensaio sobre fatores e tendências da mudança cultural das tribos índias em contato com o mundo dos brancos. Tese (Livre Docência)- Faculdade de Filosofia, Letras e Ciências Humanas, Universidade de São Paulo, São Paulo, 1964.

. Educação indígena. Revista do Arquivo Municipal. São Paulo, v. CLXXXVI, n. 37, 1974, p. 7-31.

TESTA, A. Q. Palavra, sentido, memória: educação e escola nas lembranças dos Guarani Mbya. 2007. Dissertação (Mestrado)Faculdade de Educação, Universidade de São Paulo, São Paulo, 2007.

VERNANT, J. P. Entre mito e política. São Paulo: EDUSP, 2002.

Recebido em 19.04.06

Aprovado em 21.06.07

Adriana Queiroz Testa, pedagoga e mestre em Educação pela Faculdade de Educação da Universidade de São Paulo, trabalha no Centro de Trabalho Indigenista e é colaboradora do Núcleo de História Indígena e do Indigenismo da USP. 